\title{
AGROECOLOGIA E EDUCAÇÃO DO CAMPO: DESAFIOS DA INSTITUCIONALIZAÇÃO NO BRASIL*
}

\author{
Romier da Paixão Sousa ${ }^{1}$
}

\begin{abstract}
RESUMO: As práticas de formação em Agroecologia no Brasil nasceram no final dos anos 1970, em contraponto ao modelo de modernizaçáo da agricultura. A partir dos anos 2000, o processo de institucionalização ganhou ênfase. O objetivo deste artigo foi analisar essas experiências formativas, baseadas nos preceitos da educaçáo do campo e seus processos de institucionalização enquanto política pública. $\mathrm{O}$ estudo foi produzido a partir da abordagem qualitativa, utilizando-se da análise documental e observação participante. Mesmo em caráter contra-hegemônico, inúmeros cursos são criados em Universidades e Institutos Federais em parceria com os movimentos sociais. Existem desafios na institucionalização e riscos quanto à perda da relação com sua matriz social de origem, os camponeses e seus territórios.
\end{abstract}

Palavras-chave: Educação do campo. Institucionalização. Agroecologia. Agricultura camponesa.

\section{AgRoECOLOGY AND RURAL EDUCATION: CHALLENGES OF INSTITUTIONALIZATION IN BRAZIL}

ABSTRACT: Formative practices on Agroecology were started in the late 1970's in Brazil to counter with the agriculture modernization model. From 2000 onwards, the process of institutionalization gained attention. The purpose of this article is to analyze such formative experiences based on the precepts of rural education and its processes of institutionalization as a public policy. The study was conducted on a qualitative approach, by document analysis and participative observation. Even in counterhegemonic conditions, several courses have been created at Universities and Federal Institutes in a partnership with social movements. There are challenges posed by institutionalization and risks regarding loss of relationship with its origin social matrix: peasants and their territories.

Keywords: Rural education. Institutionalization. Agroecology. Peasant agriculture.

\footnotetext{
*Este artigo apresenta resultados do Projeto de Pesquisa de Doutorado: "Educación profesional y sabidurías de los jóvenes campesinos en la Amazonía: una reflexión desde la agroecología política”, desenvolvido sob orientação do Professor PhD Manuel González de Molina Navarro, no Programa de Pós-graduação em Estudios Medioambientales da Universidad Pablo de Olavide - Sevilla-Espanha. ${ }^{1}$ Instituto Federal de Educação, Ciência e Tecnologia do Pará, Programa de Pós-graduação em Desenvolvimento Rural e Gestão de Empreendimentos Agroalimentares - Castanhal (PA), Brasil. E-mail: romier.sousa.ifpa@gmail.com
} DOI: 10.1590/ES0101-73302017180924 


\title{
AGRoÉCOLOGIE ET L'ÉDUCATION RURALE: LES DÉFIS DE I'INSTITUTIONNALISATION AU BRÉSIL
}

\begin{abstract}
RESUMÉ: Les pratiques de formation en Agroécologie au Brésil sont nées vers la fin des années 1970, par opposition au modèle de modernisation de l'agriculture. À partir des années 2000, le processus d'institutionnalisation a gagné en importance. L'objectif de cet article est d'analyser ces expériences de formation, basées dans les préceptes de l'éducation pour la campagne et ses processus d'institutionnalisation en tant que politique publique. L'étude se fonde sur une approche qualitative, par moyen d'analyse documentaire et observation participante. Même à contrecourant, plusieurs programmes d'enseignement supérieur ont été mis en place dans les Universités et Instituts Fédérales en partenariat avec les mouvements sociaux. Il y a des défis posés par l'institutionnalisation et des risques relatives à la déconnexion avec la matrice sociale d'origine : les paysans et ses territoires.
\end{abstract}

Mots-clés: Education rurale. Institutionnalisation. Agroécologie. L'agriculture paysanne.

\section{Introdução}

$\mathrm{M}$

uitos são os estudos que fazem uma avaliação crítica dos impactos sociais e culturais da modernização da agricultura no Brasil, expressos especialmente nos modelos de extensão rural e educação agrícola desenvolvidos a partir dos anos 1960 (FREIRE, 2008; CAPORAL, 1998; CAPORAL; COSTABEBER, 2002; KOLLER; SOBRAL, 2010). As críticas realizadas apontaram como a educação agrícola e a extensão rural foram usadas como uma espécie de "correia de transmissão" para a divulgação das tecnologias contidas nos pacotes da revolução verde, aqui entendida como um conjunto de tecnologias geradas em centros de pesquisas ou instituiçóes de educação agrícola, a fim de aumentar a produtividade, com base na utilização de sementes geneticamente melhoradas, uso de fertilizantes químicos e agrotóxicos, motomecanização e uso de irrigação (MUSSOI, 2011).

Para alcançar esse objetivo, houve uma reorientação da extensão, pesquisa e formação profissional para incorporar e divulgar os "modernos pacotes tecnológicos", como de aplicação universal, projetados para maximizar o rendimento dos cultivos e criaçóes de animais em situaçóes ecológicas muito diferentes. Técnicos agrícolas, agrônomos e veterinários, formados de acordo com a lógica da modernização, aprofundaram a disseminação do modelo baseado na artificialização da natureza (CAVALLET, 1999).

Tal processo modificou completamente as formas de os camponeses se relacionarem com os seus agroecossistemas. No geral, os agricultores eram vistos 
como meros depósitos de pacotes tecnológicos, gerados nos centros de pesquisas e escolas de ensino superior agrícola. Muitas práticas centenárias desenvolvidas pelos agricultores familiares camponeses (VAN DER PLOEG, 2008) foram perdidas ou invisibilizadas em função dessa nova forma de fazer agricultura. Nas escolas de formação em Ciências Agrárias, essas sabedorias foram totalmente ignoradas e, em geral, tratadas com preconceito.

A implementação de um conjunto de novas tecnologias, como sementes melhoradas, fertilizantes químicos e agrotóxicos, levou muitos agricultores a abandonar todas as práticas historicamente construídas, e houve não somente mudança na base técnica, mas também na lógica de gestâo do conhecimento, pois com a perda de sementes nativas, por exemplo, foram perdidos os conhecimentos necessários para lidar com essas sementes. Isso também aconteceu com o uso da matéria orgânica e outras práticas que os agricultores deixaram de realizar ou deixaram de tornar mais visíveis. Toledo e Barrera-Bassols (2015) chamaram de perda da memória biocultural ${ }^{1}$.

Porém, nos últimos anos, os agricultores familiares camponeses, por meio de suas organizaçóes e movimentos sociais, reagiram e têm construído formas de lutas e resistências em todo o mundo contra essa perspectiva hegemônica de difusão do conhecimento, experimentando e colocando em prática inúmeras iniciativas de educação, pesquisa e extensão com base nos princípios da agroecologia e preceitos da educação do campo (SOUSA, 2015).

O presente artigo versa sobre o processo de institucionalização da educação em agroecologia com os preceitos da educação do campo no Brasil. Busca refletir sobre os avanços e desafios da criação de cursos de agroecologia em uma perspectiva contra-hegemônica nas ciências agrárias. Reflete ainda sobre a histórica inter-relação entre a agroecologia e a educação do campo como estratégias de superação de uma concepção de ciência dominante, entendida como modelo de racionalidade que preside a ciência moderna. "Modelo global (ocidental) de racionalidade científica que, entre outras características, ostensivamente nega outras formas de produção de conhecimento" (SANTOS, 2011, p. 60-61).

O texto foi produzido a partir de pesquisas realizadas nos últimos dez anos a partir do acompanhamento dos diversos espaços de debate e reflexão sobre educação do campo e agroecologia no Brasil. Foram utilizadas as técnicas de análise documental, pesquisa bibliográfica e pesquisa participante a partir de uma abordagem qualitativa.

\section{Agroecologia e educação do campo: uma construção contra-hegemônica no campo e na Universidade}

$\mathrm{Na}$ década de 1970, tiveram início várias críticas à perspectiva de formação baseada na modernização da agricultura, impulsionadas pelos impactos 
negativos que ocorreram em áreas rurais, especialmente do ponto de vista do uso indiscriminado de agrotóxicos e o êxodo rural causado pelo aprofundamento da estrutura agrária concentradora e desigual. A esse respeito, iniciaram-se dois movimentos quase paralelos. Por um lado, os camponeses, expulsos de suas organizaçôes nacionais, devido à açáo dos militares, buscaram novas formas de articulação coletiva e encontraram nas Comunidades Eclesiais de Base (CEBs) - um campo mais progressista da Igreja Católica - uma oportunidade para a reorganização política, social e metodológica. Por outro lado, técnicos da extensão rural, intelectuais das ciências agrárias e sociais e estudantes iniciaram um movimento de reflexáo sobre o impacto da modernização e começaram a discutir tecnologias alternativas para os camponeses.

Foi a partir da valorização de ambientes de organização sociopolítica criados pela CEB que o movimento social do campo no Brasil incorporou os preceitos da educação popular, e, ao discutir a realidade local dos camponeses e seus modos de produção, deu os primeiros passos na construção do enfoque agroecológico, propondo alternativas ao modelo hegemônico de produção agroindustrial (GOMES DE ALMEIDA, 2009).

Paralelamente, a crítica ao uso excessivo de agrotóxicos e seu impacto na natureza mobilizou grupos de profissionais das ciências agrárias, que constituíram uma resistência científica e acadêmica no Brasil (SOUSA; MARTINS, 2013). Essa resistência científica, realizada por técnicos da extensão rural, pesquisadores, educadores e estudantes, teve seu ponto alto de articulação inicial nos anos 1980, com os Encontros Brasileiros da Agricultura Alternativa (EBAs), que proporcionaram debates sobre a então chamada agricultura alternativa, os problemas experimentados pela modernização da agricultura, entre outros temas de relevância naquele período. Os trabalhos de Petersen e Almeida (2004), Luzzi (2007), Gomes de Almeida (2009) e Padula et al. (2013) são referências sobre esse histórico.

A partir da década de 1990, iniciou-se uma transição de uma assessoria mais focada na disseminação de práticas tecnológicas específicas para uma abordagem que estabeleceu o agroecossistema como unidade de análise e intervenção (SCHMITT, 2009). Essa abordagem tornou possível a concepção de espaços sociais de aprendizagem, nos quais os técnicos buscavam entender a racionalidade dos agricultores assistidos e, junto com estes, iniciavam a construção de inovaçóes sociais adaptadas às suas diversas realidades socioculturais e biofísicas. Essa mudança no papel da tecnologia desencadeou uma série de eventos em abordagens metodológicas. Petersen (2007) destaca:

[...] Em vez de conceber a tecnologia como um produto acabado, volta-se, cada vez mais, para o estímulo aos processos sociais de inovação tecnológica [...] Com estes procedimentos, desloca-se a atençáo exclusiva dos produtos da inovação (as tecnologias) para que a ação dos agentes de inovação técnica 
também seja focalizada. Assim, de passivas receptoras das tecnologias, as famílias são estimuladas a assumirem ativamente seu papel como agentes de inovação e disseminação de conhecimentos (PETERSEN, 2007, p. 13).

Essa mudança metodológica não ocorreu de forma linear entre as organizaçóes e foi o resultado de um longo processo de aprendizagem entre técnicos, pesquisadores e agricultores camponeses. A introdução do agroecossistema como unidade de análise trouxe o desafio de pensar uma assessoria técnica para além da mudança técnica, tendo a necessidade de mobilizar outros conhecimentos nas áreas de ciências sociais que, muitas vezes, os técnicos em Ciências Agrárias não possuíam. A partir desse momento, houve a busca por aprofundamentos no debate sobre a educação e a formação profissional para atuar com a agricultura familiar camponesa.

Entre os anos de 1999 e 2002, houve inúmeros eventos importantes que promoveram reflexôes sobre a construção do conhecimento agroecológico e, em 2002, foi criada a Articulação Nacional de Agroecologia (ANA), uma espécie de rede de redes, que envolve movimentos sociais, organizaçóes não governamentais e organizaçôes locais de camponeses em todo o Brasil (PADULA et al., 2013).

Todas essas articulaçóes e açóes desenvolvidas pelo movimento agroecológico no Brasil, mesmo com profunda influência na proposição de políticas públicas no campo da agroecologia e vinculados ao desenvolvimento das resistências políticas, acadêmicas e científicas juntamente com as organizações dos agricultores familiares camponeses, até então tinham pouca ou nenhuma institucionalidade no âmbito das Instituições de Ensino Superior (IES) e de Instituições de Educação Profissional e Tecnológica (IEPT). Pode-se dizer que uma das formas de romper com essa barreira foi a criação do Programa Nacional de Educação na Reforma Agrária (Pronera), em 1998, iniciando a implementação de ações de formação por dentro do aparelho do Estado, fortemente influenciado pelos movimentos sociais do campo, em atenção às suas reivindicaçôes de educação no espaço rural.

O Pronera surgiu da demanda de um conjunto de organizaçóes e movimentos sociais, junto com grupos de professores e pesquisadores das universidades que naquele momento buscavam consolidar uma nova concepção de educação no espaço rural, expressa no conceito de educação do campo. Este conceito nasceu da crítica do conceito, dos princípios e das práticas que orientaram a educaçáa rural e agrícola desde os anos 1980. Movimentos sociais, especialmente o Movimento dos Trabalhadores Rurais Sem-Terra (MST), e professores das universidades realizaram uma proposta para estabelecer o que foi denominado de paradigma da "Educaçáo do Campo" (ARROYO et al., 2004; MOLINA, 2006; CALDART, 2002; 2004).

Para Caldart (2009, p. 39), "a educação do campo nasceu como crítica à realidade da educação brasileira, particularmente à situação educacional do povo 
brasileiro que trabalha e vive no/do campo". É fruto de uma intensa mobilização dos movimentos camponeses, com uma proposta para desenvolver novas metodologias de ensino e propor políticas públicas diferenciadas para as populaçôes dos espaços rurais. De acordo com Caldart (2012, p. 257), a educação do campo é um "fenômeno da atual realidade brasileira", sendo considerada uma "categoria de análise" das práticas e políticas de educação de trabalhadores e camponeses em seus territórios. Para a referida autora, os processos intensivos de lutas, levadas a cabo pelos movimentos sociais do campo; os confrontos com a força ofensiva neoliberal no país, criada na década de 1990; e as experiências educacionais inovadoras são a base para o avanço da construçáo coletiva do paradigma da educação do campo.

É nesse contexto de disputas de espaços políticos pelos camponeses e em um ambiente de contradiçóes que o Pronera se estabelece. Ligado ao Instituto Nacional de Colonização e Reforma Agrária (Incra), possui como estratégia, em seus primeiros anos, apoiar cursos de alfabetização e ampliação da escolarização, em nível fundamental para os assentados da reforma agrária, dado o alto índice de pessoas não letradas no campo. Esses processos educativos desenvolviam-se a partir da relaçáo de parceria entre o Incra, movimentos sociais e as universidades. No entanto, com o avanço do programa, os movimentos sociais começaram a demandar a elevação de escolaridade no âmbito da formação técnica profissional e de nível superior, visando à preparaçáo de quadros técnicos que pudessem atuar de maneira mais comprometida e com a compreensão da realidade dos territórios rurais. A ideia era formar novos profissionais de Ciências Agrárias para realizar assessoria técnica nos assentamento da Reforma Agrária.

Molina e Jesus (2010, p. 36) ressaltam que

[...] foram priorizados cursos relacionados ao apoio à produção, na perspectiva de contribuir com a mudança da matriz tecnológica das áreas reformadas - incorporando os princípios da agroecologia. A exemplo, foram apoiados cursos técnicos no âmbito da agroecologia e da administraçáo de cooperativas.

Os primeiros cursos foram de técnicos em Agropecuária com enfoque agroecológico e tinham como objetivo formar profissionais para atuar na assessoria técnica dos movimentos sociais.

Houve muitos conflitos iniciais entre os movimentos e a burocracia das universidades e escolas agrotécnicas (atualmente, Institutos Federais), tendo em vista as lógicas positivistas, em especial das Ciências Agrárias, por serem historicamente conservadoras em suas formas de ensino e pensamento na educação. Geralmente, esses cursos foram motivados pelas demandas dos movimentos em determinados territórios associados a grupos de professores das universidades que já trabalhavam, de alguma forma, com educação nos assentamentos rurais. 
A formação em cursos com enfoque agroecológico e educaçáo do campo, com apoio do Pronera/Incra, ganhou espaço entre as instituiçôes de ensino profissional e universitário. Mas, nas regióes em que as dinâmicas de assentamentos rurais estavam associadas a grupos de professores e instituiçôes de ensino, esses processos foram mais intensos. Diversos cursos surgiram com ênfase em Agroecologia, como os de Agrofloresta, Agropecuária, Agronomia, Residência Agrária, Cooperativismo e Agroindústria (MOLINA et al., 2014).

No entanto, ressalta-se que o caráter agroecológico do curso não pode ser enxergado apenas como a introdução de algumas questóes isoladas, como uma mudança na nomenclatura das disciplinas ou inserção de "tecnologias verdes”. É necessário, no mínimo, construir uma formação com base nas diferentes dimensóes da agroecologia. Inúmeros autores têm refletido sobre o conceito de agroecologia, a partir de sua perspectiva ecológico-agronômica, socioeconômica e político-cultural (ALTIERI, 1999; GLIESSMAN, 2005; CASADO et al., 2000; SEVILLA GUSMÁN, 2006; GONZÁLEZ DE MOLINA, 2011; entre outros). Nesse sentido, a agroecologia não pode ser vista meramente como substituição de insumos ou mesmo na dimensão da produção agrícola e, sim, no conjunto de seus aspectos, em uma lógica da multidimensionalidade. Neste texto há um enfoque mais específico na dimensão político-cultural da agroecologia (GONZALEZ DE MOLINA, 2011), entendida como a necessidade de aprofundar aspectos políticos de organizaçáo social, assim como refletir sobre os diferentes marcos "institucionais e cognitivos" (PEÑA, 2011, p. 24) que regem as instituiçóes educacionais e a busca por afirmação de políticas públicas por grupos sociais marginalizados.

A partir dessa dimensão mais política da agroecologia, é possível dizer que, no Brasil, o enfoque agroecológico e a educação do campo têm a mesma base social de construção inicial - a resistência dos agricultores familiares camponeses e seu processo de reorganizaçáo a partir dos movimentos sociais. Caporal e Petersen (2011) ressaltam que uma das características marcantes da agroecologia no Brasil é um vínculo com a defesa da agricultura familiar camponesa como base social de estilos sustentáveis de desenvolvimento rural.

A educação do campo se estabelece a partir dessa base social, questionando náo somente as práticas pedagógicas baseadas no ruralismo pedagógico e o tecnicismo das escolas agrícolas (CALDART, 2008), mas também o paradigma que sustenta essa concepçáo de ensino e, principalmente, o modelo de campo estabelecido a partir do paradigma dominante, baseado na modernização.

A defesa de uma nova proposta de desenvolvimento rural e a negaçáo do modelo amparado no agronegócio são partes integrantes dessa aproximação político-filosófica da agroecologia com e a educação do campo. A disputa social e a defesa de mudanças estruturais no campo, como a proposta da reforma agrária massiva no Brasil, também são características comuns dos dois enfoques. Nesse sentido, isso significa claramente uma postura contra-hegemônica dos dois enfoques, con- 
siderando o atual modo de produção agroindustrial e do conhecimento estabelecido em nossa sociedade (SOUSA, 2017).

As críticas aos métodos lineares e unidirecionais de produção e difusão de conhecimentos são totalmente semelhantes nas duas abordagens. A busca de uma relação educador-educando, técnico-camponês, de forma mais horizontal e participativa, é constantemente perseguida nos cursos de formação profissional agroecológica. A adoção de uma educação crítica e transformadora também é buscada como estratégia central.

A defesa de uma produção de conhecimento alicerçada na relação direta entre o conhecimento científico e a sabedoria dos povos do campo - a partir do diálogo de saberes - usando a problematização da realidade; a revalorização dos conhecimentos sociais dos camponeses; a geração e a disseminação de tecnologias adaptadas às realidades territoriais, respeitando o conhecimento e não degradando o meio ambiente; a transformação da realidade social das famílias camponesas; e a produção de alimentos saudáveis para seu consumo e o abastecimento dos mercados locais são alguns dos elementos centrais da mudança metodológica e estáo inclusos na educação do campo com enfoque agroecológico (SOUSA, 2015).

\section{De cursos a partir de projetos a projetos de cursos: a institucionalização da agroecologia nas universidades e Institutos Federais}

A formação em Agroecologia com enfoque na educação do campo nas universidades e Institutos Federais, em grande medida, iniciou-se a partir de cursos que foram ofertados em funçáo de projetos apresentados ao Pronera/Incra e encampados por coletivos de professores, técnicos e movimentos nos diversos territórios do Brasil. Esses cursos funcionaram como importantes catalisadores de experiências de formação alternativa, mas com dificuldades de se manter após a conclusão dos projetos. Santos et al. (2010, p. 10) refletem que:

[...] ao financiar cursos formais de educação superior e técnica, o Pronera contribui para uma reflexão crítica do ensino tradicional transmitido nas instituiçóes públicas. No caso específico do ensino de Ciências Agrárias, estes cursos formais executados em parceria com os assentados, abrem espaço para um verdadeiro diálogo de conhecimentos entre a universidade e os camponeses, provocando uma revisáo crítica dos currículos tradicionais.

Uma das aprendizagens no processo de construção dos cursos em Agroecologia com enfoque na educação do campo nessas instituições foi a promoção de reflexóes coletivas sobre os limites do ensino tecnicista nas escolas, em especial 
de Ciências Agrárias, proporcionando mudanças em currículos e até mesmo em estruturas gerais das instituições de ensino, como a construção de um campus do Instituto Federal totalmente voltado às práticas de ensino da Agroecologia e educação do campo (MARINHO, 2016).

Porém, a natureza do público principal do Pronera/Incra — jovens e adultos camponeses provenientes dos assentamentos rurais — deixa milhares de jovens com outras territorialidades sem a possibilidade de acesso a esse tipo de formação. Não existe, ainda hoje, uma política pública nacional para o ensino médio e superior de camponeses, especialmente aqueles que estão fora das áreas de assentamentos rurais, com uma proposta diferenciada de formação, que adote os preceitos da educação do campo como matriz pedagógica principal.

A maioria das propostas dos movimentos sociais rurais de reformulação da educação são açóes contra-hegemônicas diante das forças conservadoras da sociedade. Geralmente, os camponeses têm ficado fora da maioria das reflexóes sobre educação e formação profissional para o desenvolvimento do espaço rural (MOLINA et al., 2014). O pensamento baseado na promoção de produtos para a exportação e na construção de um conhecimento fragmentado é hegemônico nos processos de formação em Ciências Agrárias. A exclusão das propostas dos camponeses tem uma razão, quase sempre ideológica, no sentido de garantir uma educação descontextualizada e centrada na formação de pessoas para engrossar as filas de mão de obra para o modelo agroindustrial, repetindo uma prática histórica no país e reforçando o marco cognitivo do agronegócio (PEÑA, 2011).

É nesse ambiente de contradiçóes que os movimentos sociais e educadores vêm se movendo na luta e na proposição de mudanças estruturais no campo da formação profissional, especialmente nas Ciências Agrárias. Diante desse fato, e aproveitando-se de um período progressista do Estado brasileiro, inúmeras iniciativas de cursos e açôes no campo da agroecologia e educaçáo do campo foram sendo criadas.

A partir de 2002 foram criados dezenas de cursos de ensino médio profissionalizante em Agroecologia, além de cursos de graduação e pós-graduação reconhecidos pelo Ministério da Educaçáo. ${ }^{2}$ Nos últimos 15 anos, uma mudança significativa iniciou-se nos espaços das IES e IEPT brasileiras. Atualmente, os cursos com apelo na perspectiva agroecológica já totalizam 162, entre todos os níveis de formação oferecidos pelas universidades, Institutos Federais e instituiçóes estaduais de ensino. Do total de cursos em Agroecologia, 122 são de ensino médio profissional, 33 são de graduação e 7 são cursos de pós-graduação. Por outro lado, há um número elevado de cursos das Ciências Agrárias e outras áreas do conhecimento que vêm sofrendo influência, mesmo que parcial, da abordagem agroecológica (SOUSA, 2015). 
A educação formal em Agroecologia é muito recente no Brasil, considerando a longa trajetória dos cursos de Agronomia e das Ciências Agrárias no país, porém já possui territorialização nacional. No entanto, é importante que fique claro que grande parte desses cursos não possui em sua matriz curricular os preceitos da educação do campo.

O crescimento destes deu-se por três grandes aspectos:

- Demanda dos movimentos sociais do campo - a partir das experiências vivenciadas com o Pronera/Incra, foram construindo espaços de manobra (VAN DER PLOEG, 2008) no âmbito das instituiçōes federais, proporcionando a institucionalizaçáo de cursos originados de projetos (SOUSA, 2011).

- Atendimento ao nicho de mercado dos orgânicos - com o crescimento da demanda por produtos orgânicos no mercado nacional, criou-se a necessidade de formar profissionais que possam ocupar esse espaço, muitas vezes com pouco ou nenhum diálogo com os movimentos sociais e suas organizaçóes.

- Expansão da rede federal de ensino profissional e tecnológica - grande parte desses cursos foram criados em função da ampliação do número de unidades de ensino vinculadas à Rede Profissional e Tecnológica no país, especialmente nas antigas Escolas Agrotécnicas (SOUSA, 2015).

Sousa (2015) revela que há uma enorme diversidade na inserção do enfoque agroecológico nas instituições de ensino no país. A educação em Agroecologia vem se institucionalizando de diferentes maneiras demonstrada em: disciplinas nos diversos cursos, grupos de estudantes, núcleos de estudos, projetos de pesquisa e extensão, cursos formais em diferentes níveis e com outras nomenclaturas, entre outras possibilidades. Essa diversidade é positiva, a partir de certo ponto de vista, ressaltando que essas iniciativas estâo se adaptando às suas realidades biofísicas, socioeconômicas e políticas. Por outro lado, há um desafio conceitual e epistemológico em sua qualificação, com o risco de a abordagem agroecológica ser perdida em sua polissemia e deixar a força conceitual que representa cair no "vazio" ou ser cooptada por forças conservadoras das ciências agrárias e do capital.

A natureza interdisciplinar (CAPORAL; COSTABEBER, 2002) ou transdisciplinar (RUIZ-ROSADO, 2006) da agroecologia não pode ser confundida com o uso indiscriminado do termo, propondo açóes que não estão dentro de seu corpus teórico e epistemológico. Há um desafio em manter ativos os princípios teóricos, metodológicos e epistemológicos com a institucionalização. Regras, regulamentos e o contexto burocrático das instituiçóes de ensino, eventualmente, podem impedir o avanço da abordagem agroecológica em uma perspectiva 
transformadora e, principalmente, tornar difícil a presença dos camponeses nesses processos formativos e o vínculo efetivo com o paradigma da educação do campo.

Sousa (2015) procura sintetizar o conjunto de açóes de educação em agroecologia e seus diferentes níveis de institucionalização de maneira esquemática. No esquema apresentado (Figura 1), existem pelo menos três níveis de institucionalidades nas quais as ações transitam. O primeiro nível é formado por cursos eventuais ofertados por entidades externas às instituiçóes de ensino e por grupos de estudantes em Agroecologia. Porém, ressalta-se que a baixa institucionalidade desses grupos de estudantes possibilita certa independência, o que muitas vezes favorece sua permanência por anos, como é o caso de grupos que existem desde o período da agricultura alternativa. Nos últimos anos, esses grupos também têm se aproximado dos movimentos sociais do campo e de sua perspectiva de educaçáo, favorecendo um diálogo intenso entre a agroecologia e a educação do campo.

O segundo nível é formado por açóes mais estruturantes, como os projetos de pesquisa e extensão, grupos de pesquisa e núcleos de estudos. Os núcleos de estudos em Agroecologia, que desenvolvem atividades de diferentes naturezas, reforçam a abordagem agroecológica no ambiente acadêmico-científico, mas estão sujeitos a mecanismos de financiamento descontínuos e voluntarismo de educandos e professores que atuam nessas ações, ou seja, não possuem uma institucionalidade garantida. De igual modo, projetos de pesquisa e extensão universitária podem sofrer a mesma dificuldade. É necessário pensar estratégias mais duradouras e apoio eficaz desses dispositivos como um mecanismo para a promoção de uma atividade institucionalizada. Sousa (2017) aponta que quanto mais os nú-

\section{Figura 1}

Níveis de institucionalização das açôes de educação em Agroecologia no Brasil.

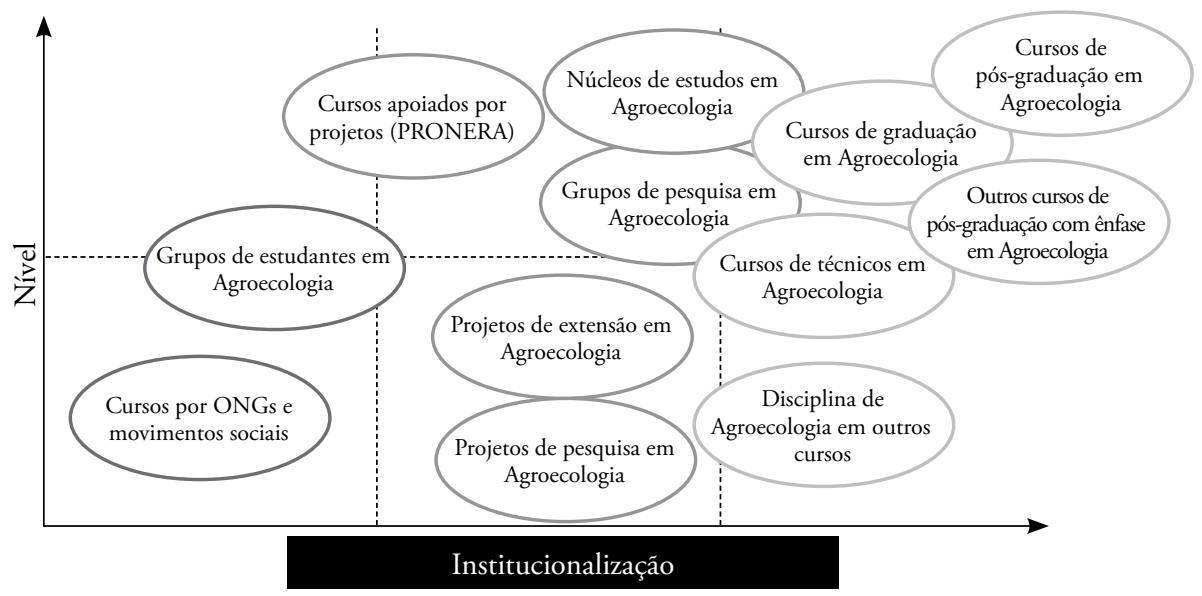

Fonte: Adaptado de Sousa (2015). 
cleos de agroecologia estão envolvidos com açôes junto aos agricultores familiares camponeses e suas organizaçóes no território onde as instituiçôes de ensino estáo inseridas, maior é sua possibilidade de continuidade, mesmo em momentos desfavoráveis à captação de recursos para manutenção das açôes de pesquisa e extensão.

Por fim, há um terceiro nível, formado por cursos. A criação dos cursos de agroecologia depende de um longo caminho institucional, gerando maior consolidação nas instituiçôes. Cursos de pós-graduação possuem regras e avaliaçôes mais rígidas e são difíceis para implementação, tendo um nível mais eficaz de institucionalidade. Todavia, quanto maior for o nível de ensino nessas instituiçóes, maior será a distância e a dificuldade de acesso pelos povos do campo (SOUSA, 2015).

É importante ressaltar que, dependendo do nível em que ela se encontra, pode permanecer como política pública independente das orientaçóes macroestratégicas do governo central, mesmo que fragilizadas. Isso se deve ao grau de autonomia que as IES possuem, o que possibilita a aprovação de cursos, projetos, núcleos em agroecologia, sem necessariamente haver interferência direta do governo federal.

A articulação das diferentes possibilidades de institucionalização em ações de educação agroecológica com preceitos na educaçáo do campo parece ser a melhor estratégia a ser estabelecida para assegurar uma abordagem eficaz e duradoura nas universidades e institutos federais, e, ao mesmo tempo, permitir o acesso e a permanência dos camponeses dos territórios. O que se tem observado no âmbito dos cursos de formação profissional e superior de Agroecologia é que a não articulaçáo desses cursos a processos concretos de desenvolvimento rural, alicerçados em estilos de agricultoras sustentáveis, perspectivas pedagógicas transformadoras e relaçóes com as lutas dos movimentos sociais do campo, cria um distanciamento com os preceitos da educação do campo.

Sem a participação mais efetiva dos camponeses nesses cursos, buscando o diálogo com seus interesses e a resolução dos problemas identificados no território, há o risco de os mesmos estarem propensos a se tornar instrumentos de formação profissional convencional ou atender apenas a nichos específicos de mercado da produção orgânica.

\section{Pistas sobre a perspectiva de formação em agroecologia com os preceitos da educação do campo}

Molina et al. (2014) desenvolvem com base em diferentes experiências de formação em Agroecologia com os preceitos da educaçáo do campo, características comuns desejáveis em cursos que consideram os princípios epistemológicos de ambos os enfoques: 
a) Problematização da realidade dos educandos, no sentido de resgatar, sistematizar e valorizar os espaços de vida como possibilidades de produçáo de conhecimento significativo [...]. b) Aprofundamento das problemáticas identificadas, mobilizando os conhecimentos técnico-científicos para contribuir com a resolução dos problemas encontrados nas comunidades rurais e/ou outros espaços de problematização [...]. c) Proposição e resolução dos problemas identificados, articulando docentes, educandos, movimentos sociais e camponeses para encontrar novas formas de produzir conhecimentos e superar as dificuldades enfrentadas, seja no campo produtivo ou no campo organizativo (MOLINA et al., 2014, p. 283).

Na mesma lógica de síntese a partir de experiências concretas de educação profissional do campo com enfoque na agroecologia na Amazônia, Sousa (2015) propóe uma "coreografia do saber-fazer da formação de jovens camponeses para a sustentabilidade agrária” (SOUSA, 2015, p. 85). O esquema proposto está baseado nas reflexóes de Toledo e Barrera-Bassols (2015) e Norgaard e Sikor (1999) (Figura 2).

\section{Figura 2}

Coreografia do saber-fazer na formação de jovens camponeses.

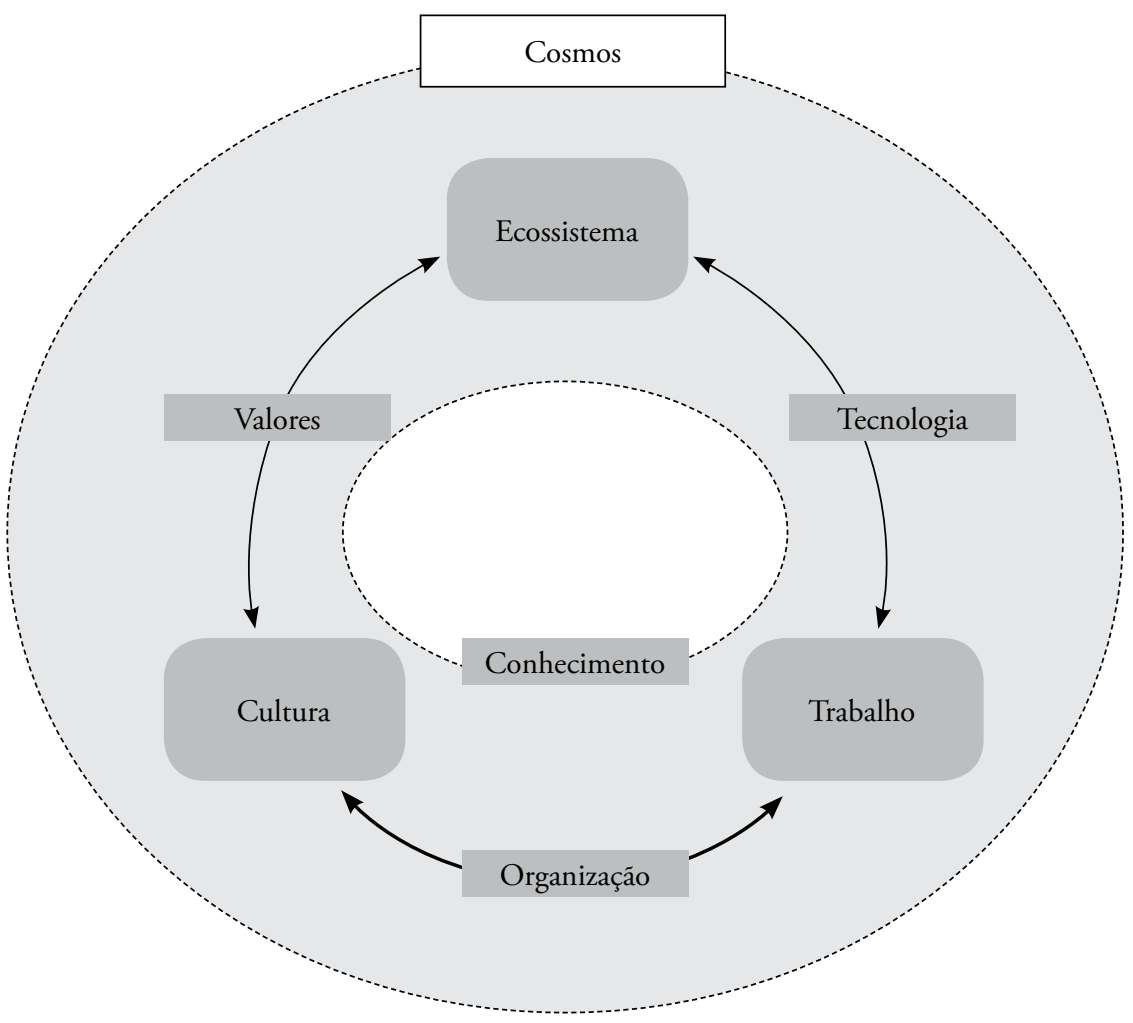

Fonte: adaptado de Sousa (2015). 
Sousa (2015) apresenta a tríade "ecossistema-trabalho-cultura" como proposta para a construção do conhecimento e sua influência na formação com enfoque agroecológico de jovens camponeses: o ecossistema como parte importante na constituição dos agroecossistemas e da paisagem agrária; o trabalho a partir da práxis no sentido da prática refletida; a cultura a partir da compreensáo do kosmos (crenças) e corpus (conhecimento) apreendido.

O ecossistema é entendido na perspectiva do contexto da realidade dos seres humanos. Não há produção de conhecimento, sem contexto, sem realidade. Assume-se aqui a ideia de Paulo Freire no sentido de que o processo de construção do conhecimento é mediado pelo mundo. $\mathrm{O}$ mundo com historicidade, em que sua leitura é parte de uma dimensão histórico-cultural para a compreensão da realidade (FREIRE, 1983b).

O contexto impóe condiçóes para a reprodução da existência humana, portanto, age sobre o trabalho feito por seres humanos para garantir a produção econômica e reprodução social. Este trabalho é entendido em seu sentido ontológico (SAVIANI, 2007), em que os seres humanos, para produzir sua própria existência, formam-se humanos e essa formação é um processo educativo, porque ele é construído a partir de experiências, erros e acertos vivenciados historicamente.

Nesse sentido, a transformação do ecossistema (contexto) por seres humanos é também uma função das relações de trabalho realizadas por eles (seres humanos) e é mediada pela tecnologia utilizada, que evolui na medida da capacidade de esses seres humanos aprenderem neste contexto. Esse processo de transformação do ecossistema por meio da ação humana, mediado pela tecnologia, gera agroecossistemas e paisagens agrárias. No entanto, a sustentabilidade agrária é mantida na medida do equilíbrio entre o uso da tecnologia e manutenção dos componentes bióticos do ecossistema.

Dessa maneira, a construção de agroecossistemas sustentáveis não é possível sem uma concepção humana da importância da manutençấo do capital ecológico (natureza viva) dos ecossistemas (VAN DER PLOEG, 2008). Assim, a cultura desempenha um papel importante nessa coreografia, uma vez que o processo de aprendizagem e ação nesse contexto (ecossistema-agroecossistema), por meio do trabalho, é o produto dos valores, crenças e conhecimentos necessários para a gestáo e o uso da natureza. Assim, o sistema de trabalho dos camponeses se aproxima da sustentabilidade, por depender da manutenção desse capital ecológico. Os camponeses constroem, em grande parte, suas crenças e sabedorias na relação direta com a natureza. São indivíduos que nasceram e desenvolveram suas práticas de trabalho e a maneira como entender o universo que os circunda (contexto) a partir da convivência direta com a natureza (TOLEDO; BARRERA-BASSOLS, 2015). 
Pensar uma pedagogia da transformaçáo socioecológica, para além de se fazer apenas diagnósticos da realidade agrária, introdução de pacotes "verdes" e reflexóes sem açôes concretas na realidade, torna-se essencial para o avanço da educação profissional do campo com enfoque na agroecologia. Para isso, é fundamental a compreensão da importância do saber camponês e sua relaçáo com o conhecimento científico.

Dessa forma, o movimento da educação do campo vem construindo as bases pedagógicas e operacionais da concepção de uma educação profissional em Agroecologia, com ênfase:

- na crítica radical ao modelo de desenvolvimento hegemônico;

- na busca da ruptura epistemológica com a ciência dominante;

- numa concepção pedagógica que valorize os territórios e a sabedoria dos povos do campo, garantindo os diferentes tempos e espaços de formação;

- bem como numa proposta de formaçáo que consiga dialogar com a realidade do campo, náo simplesmente procurando conhecê-la, mas também transformá-la.

\section{Notas}

1. A memória biocultural está relacionada ao acúmulo histórico de conhecimentos adquiridos pelos seres humanos na relação com natureza (TOLEDO; BARRERA-BASSOLS, 2015).

2. O Ministério da Educação possui Catálogos Nacionais dos Cursos Técnicos e Superiores, nos quais se encontram registrados os cursos de técnico em Agroecologia, tecnológico em Agroecologia e bacharel em Agroecologia.

\section{Referências}

ALTIERI, M.A. The ecological role of biodiversity in agroecosystems. Agriculture, Ecosystems \& Environment, v. 74, n. 1, p. 19-31, 1999.

ARROYO, M.G.; Caldart, R.S.; MOLINA, M.C. (Orgs.). Por uma educação do campo. Petrópolis: Vozes, 2004.

CALDART, R.S. Dicionário de educação no campo. Rio de Janeiro: Editora da Expressão Popular, 2012.

Educação do campo: notas para uma análise de percurso. Trabalho, Educação e Saúde, Rio de Janeiro, v. 7, n. 1, p. 35-64, 2009.

. Elementos para construção do projeto político e pedagógico da educação do campo. Contribuições para a construção de um projeto de educação do campo. Brasília: Articulação Nacional por uma Educação do Campo, 2004. v. 5. (Coleção Por Uma Educação do Campo). 
CALDART, R.S. Sobre educação do campo. In: Santos, C.A. (Org.). Por uma Educação do Campo. Brasília: Incra/MDA, 2008.

CAPORAL, F.R. La extensión agraria del sector público ante los desafios del desarrollo sostenible: el caso de Rio Grande do Sul, Brasil. 517 f. Tese (Doutorado em Agroecología, Campesinado e História) - ISEC-ETSIAN, Universidad de Córdoba, Córdoba, Espanha, 1998.

CAPORAL, F.R.; COSTABEBER, J.A. Agroecologia: enfoque científico e estratégico. Agroecologia e Desenvolvimento Rural Sustentável, Porto Alegre, v. 3, n. 2, p. 13-16, 2002.

CAPORAL, F.R.; PETERSEN, P. Agroecologia e políticas públicas na América Latina: o caso do Brasil. Agroecología, v. 6, p. 63-74, 2011.

CASADO, G.; MOLINA, M.G.; GUZMÁN, E.S. Introducción a la agroecología como desarrollo rural sostenible. Madri: Mundi-Prensa, 2000.

CAVALLET, V.J. A formação do engenheiro agrônomo em questão: a expectativa de um profissional que atenda as demandas sociais do século XXI. Tese (Doutorado em Educaçáo) - Faculdade de Educação, Universidade de São Paulo, São Paulo, 1999.

FREIRE, P. Educação como prática da liberdade. Rio de Janeiro: Paz e Terra, 1983a. Extensão ou comunicação. Rio de Janeiro: Paz e Terra, 2008. . Pedagogia do oprimido. 17. ed. Rio de Janeiro: Paz e Terra, 1983b.

GLIESSMAN, S.R. Agroecologia: processos ecológicos em agricultura sustentável. Porto Alegre: Universidade Federal do Rio Grande do Sul, 2005.

GOMES DE ALMEIDA, S. Construção e desafios do campo agroecológico brasileiro. In: Petersen, P. (Org.). Agricultura familiar camponesa na construção do futuro. Rio de Janeiro: ASPTA, 2009. p. 67-83.

GONZÁLEZ DE MOLINA, M. de Introducción a la Agroecología. Madri: Sociedad Española de Agricultura Ecológica, 2011.

KOLLER, C.; SOBRAL, F. A construção da identidade nas escolas agrotécnicas federais: a trajetória da COAGRI ao CONEAF. In: Moll, J. (Org.). Educação profissional e tecnológica no Brasil contemporâneo: desafios, tensôes e possibilidades. Porto Alegre: Artmed, 2010.

LUZZI, N. O debate agroecológico no Brasil: uma construção a partir de diferentes atores sociais. Tese (Doutorado) - Universidade Federal Rural do Rio de Janeiro, Rio de Janeiro, 2007.

MARINHO, D.L. Rompendo as cercas e construindo saberes: a juventude na construção da educação profissional do campo no sudeste do Pará. Recife: Imprima, 2016.

MOLINA, M.C. Educação do Campo e pesquisa: questôes para reflexão. In:

(Org.). Educação do campo e pesquisa. Questôes para reflexão. Brasília: Ministério do Desenvolvimento Agrário, 2006.

MOLINA, M.C.; JESUS, S.M. Contribuiçôes do Pronera à educação do campo no Brasil: reflexôes a partir da tríade: campo-política pública-educação. In: SANTOS, C.A. dos; MOLINA, M.C.; JESUS, S.M. dos S. A memória e história do Pronera. Brasília: Pronera/ Incra/MDA, 2010. 
MOLINA, M.C.; SANTOS, C.A; MICHELOTTI, F.; SOUSA, R.P. (Orgs.). Práticas contra-hegemônicas na formação dos profissionais das Ciências Agrárias: reflexôes sobre Agroecologia e Educação do Campo nos cursos do Pronera. Brasília: MDA, 2014. 292 p.

MUSSOI, E.M. Política de extensión rural agroecológica en Brasil: avances y desafíos en la transición en las instituciones oficiales. Investigación (Postdoctorado) - Universidad de Córdoba/Universidad Internacional de Andalucía, Espanha, 2011.

NORGAARD, R.B.; SIKOR, T.O. Metodología y práctica de la agroecología. In: ALTIERI, M.A.; HECHT, S.; LIEBMAN, M.; MAGDOFF, F.; NORGAARD, R.; SIKOR, T.O. Agroecología: Bases científicas para una agricultura sustentable. Montevideo: Nordan, 1999. p. 27-42.

PADULA, J. et al. Os caminhos da agroecologia no Brasil. In: GOMES, J.C.C.; ASSIS, W.S. (Orgs.). Agroecologia: princípios e reflexôes conceituais. Brasília: Embrapa, 2013. p. 37-73.

PEÑA, F.G. Ecología política y agroecología: marcos cognitivos y diseño institucional. Agroecología, v. 6, p. 21-28, 2011.

PETERSEN, P.; ALMEIDA, S.G. de. Rincóes transformadores: trajetória e desafios do movimento agroecológico brasileiro: uma perspectiva a partir da Rede PTA. Rio de Janeiro: ASPTA, 2004.

PETERSEN, P.; DIAS, A. (Org.) Construção do conhecimento agroecológico: novos papéis, novas identidades. . Brasília: Articulação Nacional em Agroecologia, 2007.

PETERSEN, P.; DAL SOGLIO, F.K.; CAPORAL, F.R. A construção de uma ciência a serviço do campesinato. Agricultura familiar camponesa na construção do futuro. Rio de Janeiro: ASPTA, 2009.

RUIZ-ROSADO, O. Agroecología: una disciplina que tiende a la transdisciplina. Interciencia, Caracas, v. 31, n. 2, p. 140-145, 2006.

SANTOS, B. de S. A crítica da razão indolente: contra o desperdício da experiência. In: . Para um novo senso comum: a ciência, o direito e a política na transiçáo paradigmática. São Paulo: Cortez, 2011.

SANTOS, C.; MICHELOTTI, F.; SOUSA, R. Educação do campo, agroecologia e protagonismo social: a experiência do Programa Nacional de Educação na Reforma Agrária (Pronera). Agriculturas, v. 7. n. 4, dez. 2010.

SAVIANI, D. Trabalho e Educação: fundamentos ontológicos e históricos. Revista Brasileira de Educação, São Paulo, v. 12, n. 34, p. 152-165, 2007.

SCHMITT, C.J. Transição agroecológica e desenvolvimento rural: um olhar a partir da experiência brasileira. In: SAUER, S.; BALESTRO, M.V. (Orgs.). Agroecologia e os desafios da transição agroecológica. São Paulo: Expressão Popular, 2009. p. 177-204.

SEVILLA GUSMÁN, E. De la Sociología Rural a la Agroecología. Barcelona: Icaria, 2006.

SOUSA, R. DA P. Educação em agroecologia: reflexôes sobre a formação contrahegemônica de camponeses no Brasil. Ciência e Cultura, v. 69, n. 2, p. 28-33, 2017. 
SOUSA, R. da P. Educación profesional y sabidurías de los jóvenes campesinos en la Amazonía: una reflexión desde la agroecología politica. Tese (Doutorado) - Universidad Pablo de Olavide, Sevilha, 2015.

Rompiendo las cercas: formación profesional y Agroecología: una mirada crítica de una experiencia en la Amazonia brasileña. Trabalho (Pós-doutorado) - Universidade de Córdoba, Córdoba, 2011.

SOUSA, R. da P.; MARTINS, S.R. Construção do conhecimento agroecológico: desafios para a resistência científico-acadêmica no Brasil. In: Costa Gomes, J.C.; Assis, W.S. de. Agroecologia: princípios e reflexóes conceituais. Brasília: EMBRAPA, 2013.

TOLEDO, V.M.; BARRERA-BASSOLS, N. A memória biocultural: a importância ecológica das sabedorias tradicionais. São Paulo: Expressão Popular, 2015.

VAN DER PLOEG, J.D. Camponeses e impérios alimentares: lutas por autonomia e sustentabilidade na era da globalização. Porto Alegre: Editora UFRGS, 2008.

Recebido em 2 de junho de 2017.

Aprovado em 9 de agosto de 2017. 